\title{
Assistência Humanizada ao Paciente Portador de Cirrose Hepática- Relato de Experiência
}

\author{
Andrade, Maisa Alves; Fontes, Mírzia Lisboa; Almeida, Thaynara Fontes; Araujo, \\ Jamilly Santos; Cartaxo, Carla Kalline Alves; Oliveira, Patricia Gois de \\ Universidade Federal de Sergipe - maisinhaalves@hotmail.com
}

\begin{abstract}
INTRODUÇÃO: a Cirrose Hepática é responsável por uma alta taxa de morbimortalidade, sendo a quinta causa de mortalidade em homens de 20 a 59 anos. Trata-se de uma doença crônica na qual ocorre substituição difusa da estrutura hepática normal por nódulos de estrutura anormal, circundados por fibrose. Não existe tratamento capaz de curar a doença, portanto a meta consiste em reduzir a progressão da mesma e prevenir o desenvolvimento de possíveis complicações. As mudanças nos hábitos alimentares e a abolição do álcool são fundamentais. OBJETIVO: Relatar a experiência vivenciada durante atividade curricular no acompanhamento à pacientes com cirrose hepática. METODOLOGIA: Tratase de um relato de experiência realizado durante estágio da disciplina Habilidades Clínicas e Atitudes II. no estudo foram desenvolvidas atividades de humanização a pacientes portadores de cirrose hepática. a atividade ocorreu no Hospital Regional de Lagarto localizado no estado de Sergipe. RESULTADOS: em acompanhamento aos pacientes portadores de cirrose hepática e familiares foram notadas a preocupação com a doença. Visto que, não possuíam nenhum conhecimento a respeito desta, foi realizada toda a sistematização da assistência em enfermagem, elaborado um plano de alta e esclarecido as dúvidas. Além disso, por se tratar de uma doença crônica, clientes e familiares receberam orientações para o autocuidado, para adesão ao tratamento e na prevenção dos possíveis agravos da cirrose. Todo o cuidado foi focado na promoção da saúde dos mesmos a fim de manter estável o quadro de saúde e garantir uma melhor qualidade de vida. CONCLUSÃO: a participação da equipe de enfermagem no cuidado ao paciente com cirrose hepática é de fundamental importância principalmente na prevenção e promoção da saúde, pois esta é uma doença crônica. com isso, pacientes crônicos recebem atenção para obter melhor qualidade de vida e evitar as complicações da doença.
\end{abstract}

Andrade, Maisa Alves; Fontes, Mírzia Lisboa; Almeida, Thaynara Fontes; Araujo, Jamilly Santos; Cartaxo, Carla Kalline Alves; Oliveira, Patricia Gois de. Assistência Humanizada ao Paciente Portador de Cirrose Hepática- Relato de Experiência. In: Anais do Congresso Internacional de Humanidades \& Humanização em Saúde [= Blucher Medical Proceedings, num.2, vol.1]. São Paulo: Editora Blucher, 2014. ISSN 2357-7282 DOI 10.5151/medpro-cihhs-10561 